\title{
Osmotically stable L forms of Haemophilus influenzae and their significance in testing sensitivity to penicillins
}

\author{
DAVID E. ROBERTS, A. INGOLD, SUSAN V. WANT, AND \\ THE LATE J. ROBERT MAY
}

From the Department of Bacteriology, Cardiothoracic Institute, Brompton Hospital, London

SYNOPSIS The sensitivity of Haemophilus influenzae to penicillins in vitro, determined either by serial antibiotic dilution in broth or by the disc method on agar, is apparently profoundly influenced by inoculum size if the results are read by macroscopic inspection. Microscopic inspection of the growth, however, reveals that the turbidity in heavily inoculated broth containing concentrations higher than the minimal inhibitory concentration is the product of $\mathrm{L}$ forms which have failed to succumb to osmotic lysis. Similarly, minute colonies appearing in the 'inhibition zone' of disc tests are composed of $\mathrm{L}$ forms. In both broth and agar tests reduction of the osmolality of the medium from 340 to $144 \mathrm{mOsm}$ per $\mathrm{kg}$ failed to bring about lysis of organisms exposed either to ampicillin or amoxycillin. The significance of this remarkable osmotic stability of haemophilus $L$ forms is discussed in relation both to testing of sensitivity of this organism to penicillins and to persistence of chronic haemophilus infections of the lower respiratory tract.

It is generally accepted that inoculum size must be carefully regulated when testing the sensitivity of a bacterial species to an antibacterial drug, since too large an inoculum may give rise to apparent resistance of an organism which is in fact fully sensitive. The importance of the 'inoculum effect', however, varies in relation to different drugs, being minimal in the testing of the sensitivity of non-penicillinaseproducing organisms to penicillin. This is illustrated, for example, by the demonstration by Rolinson and Stevens (1961) that the minimal inhibitory concentration (MIC) of ampicillin for Salmonella typhi varied only between $0.6 \mu \mathrm{g}$ per $\mathrm{ml}$ and $0.25 \mu \mathrm{g}$ per $\mathrm{ml}$ when the inoculum size was varied between $1 / 10$ and $1 / 100000$ of an overnight broth culture. In contrast, a similar variation of inoculum size caused a tenfold change in the MIC of tetracycline.

In the course of extensive testing of the sensitivity of strains of Haemophilus influenzae to ampicillin and, more recently, amoxycillin, we have become aware that apparent resistance can readily result from the use of an inoculum only moderately in excess of that usually regarded as appropriate for general sensitivity testing, and microscopic inspection of the organisms surviving in drug concentrations higher than the MIC has shown them to be

Received for publication 19 March 1974.
L forms which have failed to succumb to osmotic lysis.

We describe here some preliminary observations on this phenomenon and discuss its significance in regard to sensitivity testing. Its possible bearing on the role of $\mathrm{L}$ forms in the persistence of chronic haemophilus infections of the respiratory tract is also considered.

\section{Material and Methods}

STRAINS OF H. INFLUENZAE

All strains were non-capsulated and had been isolated from the sputum of patients attending the Brompton Hospital.

NUTRIENT BROTH

The standard broth used was that devised by M. R. Breach and his colleagues at Westminster Hospital (Baker and Breach, 1967) to which were added nicotinamide adenine dinucleotide (NAD) and haemin to enhance growth of $H$. influenzae. Its composition (per litre of tap water) was as follows: proteose peptone (Oxoid) $10 \mathrm{~g}$, Lab-lemco (Oxoid) $10 \mathrm{~g}, \mathrm{NaCl} 5 \mathrm{~g}, \mathrm{MgCl}_{2} 6 \mathrm{H}_{2} \mathrm{O} \cdot 1 \mathrm{~g}$, liver digest (Oxoid) $3 \mathrm{~g}$, yeast extract (Oxoid) $3 \mathrm{~g}$, NAD (BDH) $3 \mathrm{mg}$, haemin (BDH) $3 \mathrm{mg}$. The osmolality of this medium was 340 mOsm per $\mathrm{kg}$. Omission of the $\mathrm{NaCl}$ and 
$\mathrm{MgCl}_{2}$, and substitution of distilled water for tap water, yielded a medium of osmolality 144 mOsm per kg.

The two variants of the medium, differing in osmolality, have been designated A (340 mOsm) and B (144 mOsm).

\section{NUTRIENT AGAR}

Solid media corresponding to the two nutrient broths were prepared by the addition of Oxoid agar no. $1,1 \mathrm{~g}$ per $100 \mathrm{ml}$.

\section{SENSITIVITY TESTS}

Determinations of MIC were made by the doubling dilution technique in broth inoculated with organisms as indicated in the text. In many of the tests the morphology of the organisms exposed to the antibiotic was subsequently determined by phasecontrast microscopy.

For disc tests on agar, standard discs (Mast Laboratories) containing $25 \mu \mathrm{g}$ ampicillin or amoxycillin were used.

\section{DEFINITION OF L FORM}

We use the term ' $L$ form' to denote a round body, about $5 \mu$ in diameter, arising from a bacillary form exposed to the action of an inhibitor of cellwall synthesis, eg, any penicillin. We have avoided use of the terms 'spheroplast' and 'protoplast' because we are at present unable to define the nature or extent of the cell-wall defect.

\section{Results}

INFLUENCE OF INOCULUM SIZE ON MIC OF AMPICILLIN FOR $S T A P H$. AUREUS

Five replicate sets of doubling dilutions of ampicillin in $0.9 \mathrm{ml}$ volumes of broth $\mathbf{A}$ were prepared. Each tube of the first set was inoculated with $0.1 \mathrm{ml}$ of an overnight broth culture of a penicillin-sensitive strain of Staph. aureus. The remaining sets were similarly inoculated with $0 \cdot 1 \mathrm{ml}$ volumes of successive 10-fold dilutions of the culture. Thus the approximate final numbers of organisms per $\mathrm{ml}$ in each set were $10^{7}, 10^{6}, 10^{5}, 10^{4}$, and $10^{3}$. After incubation overnight at $37^{\circ} \mathrm{C}$ the MIC in each set was noted as the lowest concentration in which no turbidity was seen.

With an inoculum of $10^{7}$ organisms per $\mathrm{ml}$, the MIC was $0 \cdot 1 \mu \mathrm{g}$ per $\mathrm{ml}$, while with an inoculum of $10^{3}$ it was $0.05 \mu \mathrm{g}$ per $\mathrm{ml}$.

\section{INFLUENCE OF INOCULUM SIZE ON MIC OF \\ AMPICILLIN FOR H. INFLUENZAE}

In table $I$ are shown the results of a similar experiment in which the effect of inoculum size upon the MIC of ampicillin for $H$. influenzae was determined. Using an inoculum of approximately $10^{7}$ organisms per $\mathrm{ml}$, the MIC, judged by visible turbidity of the growth, was greater than $10 \mu \mathrm{g}$ per $\mathrm{ml}$, whereas when the inoculum was reduced to $10^{5}$ organisms per $\mathrm{ml}$ the MIC was $0.6 \mu \mathrm{g}$ per $\mathrm{ml}$.

Table II shows the findings of microscopic inspec-

\begin{tabular}{|c|c|c|c|c|c|c|c|c|}
\hline \multirow[t]{2}{*}{$\begin{array}{l}\text { Inoculum Size } \\
\text { (organisms per } m l \text { ) }\end{array}$} & \multicolumn{8}{|c|}{$\begin{array}{l}\text { Macroscopic Turbidity after Incubation in Broth A Containing Ampicillin at Concentration } \\
(\mu \mathrm{g} \text { per } \mathrm{ml})\end{array}$} \\
\hline & 10 & 5 & 2.5 & $1 \cdot 2$ & 0.6 & $0 \cdot 3$ & $0 \cdot 1$ & None \\
\hline $\begin{array}{l}10^{7} \\
10^{6} \\
10^{5}\end{array}$ & $\begin{array}{l}+++^{2} \\
+2\end{array}$ & $\begin{array}{l}+++ \\
+\end{array}$ & $\begin{array}{l}+++ \\
+ \\
-\end{array}$ & $\begin{array}{l}+++ \\
+ \\
-\end{array}$ & $\begin{array}{l}+++ \\
+ \\
-\end{array}$ & $\begin{array}{l}+++ \\
+++ \\
+++\end{array}$ & $\begin{array}{l}+++ \\
+++ \\
+++\end{array}$ & $\begin{array}{l}+++ \\
+++ \\
+++\end{array}$ \\
\hline
\end{tabular}

Table I Influence of inoculum size on the MIC of ampicillin for a strain of $\mathrm{H}$. influenzae

${ }^{1}+,++=$ degrees of turbidity, $-=$ no turbidity

\begin{tabular}{|c|c|c|c|c|c|c|c|c|}
\hline \multirow[t]{2}{*}{$\begin{array}{l}\text { Inoculum Size } \\
\text { (organisms per } \mathrm{ml} \text { ) }\end{array}$} & \multicolumn{8}{|c|}{$\begin{array}{l}\text { Microscopic Appearance of Organisms after Incubation in Broth A Containing Ampicillin at Concentration } \\
(\mu \mathrm{g} \text { per } \mathrm{ml})\end{array}$} \\
\hline & 10 & 5 & $2 \cdot 5$ & $1 \cdot 2$ & 0.6 & $0 \cdot 3^{1}$ & 0.1 & None \\
\hline $\begin{array}{l}10^{7} \\
10^{6} \\
10^{5}\end{array}$ & $\begin{array}{l}\mathbf{L}+++^{2} \\
\mathbf{N}-{ }^{-3} \\
\mathbf{L}+ \\
\mathbf{N}- \\
\mathbf{L} \pm \\
\mathbf{N}-\end{array}$ & $\begin{array}{l}\mathbf{L}+++ \\
\mathbf{N}- \\
\mathbf{L}+ \\
\mathbf{N}- \\
\mathbf{L} \pm \\
\mathbf{N}-\end{array}$ & $\begin{array}{l}\mathbf{L}+++ \\
\mathbf{N}- \\
\mathbf{L}+ \\
\mathbf{N}- \\
\mathbf{L} \pm \\
\mathbf{N}-\end{array}$ & $\begin{array}{l}\mathbf{L}+++ \\
\mathbf{N}- \\
\mathbf{L}+ \\
\mathbf{N}- \\
\mathbf{L} \pm \\
\mathbf{N}-\end{array}$ & $\begin{array}{l}\mathbf{L}+ \\
\mathbf{N}- \\
\mathbf{L}+ \\
\mathbf{N}- \\
\mathbf{L} \pm \\
\mathbf{N}-\end{array}$ & $\begin{array}{l}\mathbf{L}- \\
\mathbf{N}++ \\
\mathbf{L}- \\
\mathbf{N}++ \\
\mathbf{L}- \\
\mathbf{N}++\end{array}$ & $\begin{array}{l}\mathbf{L}- \\
\mathbf{N}+++ \\
\mathbf{L}- \\
\mathbf{N}+++ \\
\mathbf{L}- \\
\mathbf{N}+++\end{array}$ & $\begin{array}{l}\mathbf{L}- \\
\mathbf{N}+++ \\
\mathbf{L}- \\
\mathbf{N}+++ \\
\mathbf{L}- \\
\mathbf{N}+++\end{array}$ \\
\hline
\end{tabular}

Table II Influence of inoculum size on the MIC of ampicillin for a strain of $\mathrm{H}$. influenzae

${ }^{1}$ Man y bacilli in the tubes containing $0.3 \mu \mathrm{g}$ ampicillin per $\mathrm{ml}$ showed filamentous structure.

$\mathbf{2}_{\mathbf{L}}=\mathbf{L}$ forms. ${ }^{3} \mathbf{N}=$ normal bacillary forms 
tion of the morphology of organisms in each tube in this experiment. Two points should be noted. First, bacillary forms were seen only in tubes containing $0.3 \mu \mathrm{g}$ or less ampicillin per ml, regardless of the size of the original inoculum. In the tube containing $0.3 \mu \mathrm{g}$ per ml many of the bacilli were filamentous. Secondly, in tubes containing $0.6 \mu \mathrm{g}$ or more ampicillin per $\mathrm{ml}$ numerous $\mathrm{L}$ forms were seen. In the tubes inoculated with $10^{7}$ or $10^{6}$ organisms per $\mathrm{ml}$ these forms were apparently responsible for the macroscopic turbidity.

Thus, if the MIC was determined from macroscopic inspection of visible turbidity there was a very pronounced inoculum effect, but this disappeared if the endpoint was taken as the lowest concentration in which no bacillary forms could be detected microscopically.

This phenomenon was also observed in tests of each of five other strains of $\boldsymbol{H}$. influenzae. In each instance, when the MIC was determined from macroscopic inspection of visible turbidity there was a striking difference between the tubes inoculated with $10^{7}$ organisms per $\mathrm{ml}$ compared with those inoculated with $10^{5}$ organisms per $\mathrm{ml}$, whereas in no case did the two readings differ by more than a factor of 2 when they were derived from microscopic inspection of the growth. In every instance $\mathrm{L}$ forms could be seen in tubes containing ampicillin concentrations in excess of the MIC, although these were present in sufficient numbers to cause dense turbidity only in the tubes inoculated with $10^{7}$

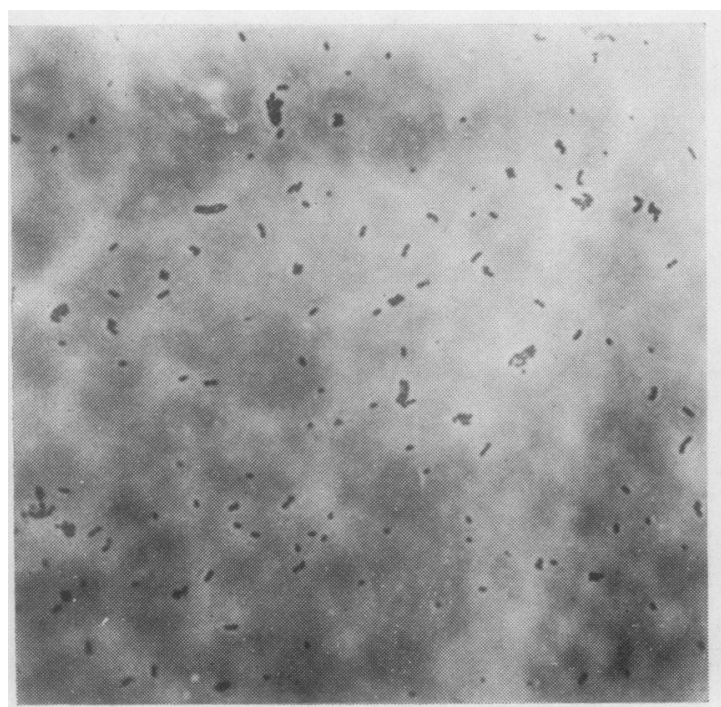

Fig Normal forms of $\mathrm{H}$. influenzae $\times 740$. organisms per $\mathrm{ml}$ or light turbidity in those inoculated with $10^{6}$ organisms per $\mathrm{ml}$.

INFLUENCE OF INOCULUM SIZE ON DISC SENSITIVITY TEST OF H. INFLUENZAE TO AMPICILLIN

Two sets of plates of nutrient agar A were inoculated by flooding with overnight broth cultures of $H$. influenzae diluted respectively 10 -fold and 70 -fold and ampicillin discs were applied to each. Identical results were obtained for each of eight strains tested. On the heavily inoculated plates 'zones of inhibition' were seen, but within the zones there was a profuse growth of tiny colonies, which, on microscopic inspection, were found to consist of $L$ forms (see figure). On the lightly inoculated plates the inhibition zones appeared clear, but microscopic inspection revealed small numbers of $L$ forms. On all plates the density of the $\mathrm{L}$ form growth diminished with decreasing distance from the disc, ie, in inverse relation to drug concentration.

THE INFLUENCE OF OSMOLALITY OF THE

MEDIUM

The MIC of ampicillin for nine strains of $H$. influenzae was compared in nutrient broths A and B. The tubes for each strain were inoculated with approximately $10^{7}$ organisms per $\mathrm{ml}$ and were incubated overnight at $37^{\circ} \mathrm{C}$. The results were recorded after both macroscopic and microscopic inspection.

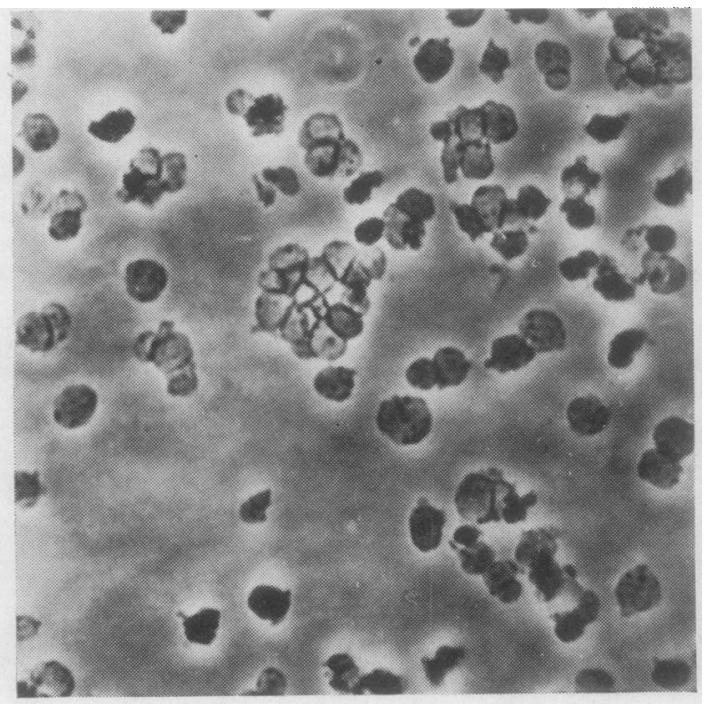

$L$ forms of $\mathrm{H}$. influenzae $\times 740$. 
Macroscopic inspection of the tubes revealed turbidity of all strains in all tubes of both media up to and including that containing $10 \mu \mathrm{g}$ ampicillin per $\mathrm{ml}$-the highest concentration tested. The turbidity given by five strains, however, was less in medium $\mathbf{B}$ than in medium $\mathbf{A}$, but, since this related also to the control tubes containing no ampicillin, it was merely a reflection of the lesser ability of medium B to support the growth of $H$. influenzae.

When the results were read microscopically, taking as the endpoint the lowest drug concentration in which no bacillary forms were seen, identical MICs were recorded in both media for each strain. The actual MIC for different strains varied from 0.6 to $1 \cdot 2 \mu \mathrm{g}$ per $\mathrm{ml}$.

Disc sensitivity tests, as described in the preceding section, were repeated on nutrient agar B with results identical to those obtained with agar A.

COMPARISON OF THE ACTIVITY OF

AMPICILLIN AND AMOXYCILLIN AGAINST

H. INFLUENZAE

The activity of amoxycillin against eight strains of $H$. influenzae was compared with that of ampicillin by the methods described above, using nutrient broth and nutrient agar of both high and low osmolalities. The only difference noted between the two drugs related to three strains for which the MIC of amoxycillin, read microscopically, was twice that for ampicillin. In all other respects all strains reacted identically to both drugs.

Burns and Devitt (1974) reported that $30 \%$ of 135 strains of $\boldsymbol{H}$. influenzae showed minute colonies within the inhibition zones of ampicillin disc sensitivity tests, compared with only $16 \%$ of 50 strains tested with amoxycillin. We have tested 39 strains against discs of both drugs on nutrient agar $\mathbf{A}$, inoculated by flooding with an overnight broth culture diluted $\frac{1}{70}$, as recommended by Burns and Devitt. All strains were sensitive to both drugs, and in no instance were macroscopically visible colonies seen in the inhibition zone.

VIABILITY OF L FORMS OF H. INFLUENZAE The ability of $\mathrm{L}$ forms of $H$. influenzae, induced by contact with ampicillin or amoxycillin, to continue to grow as $\mathrm{L}$ forms or to revert to bacillary forms on subculture on antibiotic-free medium is currently being studied. It can be stated at present that forms induced in drug concentrations not much higher then the MIC can readily revert to bacillary forms when transferred to antibiotic-free medium. There is some evidence, however, to suggest that $L$ forms induced by much higher drug concentrations may lose their capacity to revert to bacillary forms. This aspect of the investigation will form the subject of a separate report.

\section{Discussion}

Our observation that the MIC of ampicillin for Staph. aureus, in a medium of high osmolality, was almost unaffected by a very wide range of inoculum size accords well with the report of Rolinson and Stevens (1961) relating to Salm. typhi and is in line with the general unimportance of the inoculum effect in the testing of non-penicillinase-producers to penicillins. Haemophilus influenzae, however, appears at first sight to behave very differently, the MIC being profoundly influenced by inoculum size; but this difference is in fact only superficial since, if the MIC is defined as 'the lowest concentration inhibitory to microscopically normal organisms, variation in inoculum size has very little effect. The property in relation to which $H$. influenzae seems to differ from other species is the remarkable osmotic stability of the L forms induced by penicillins. Greenwood and O'Grady $(1969,1972)$ have reported differences in susceptibility to osmotic lysis of spheroplasts of Escherichia coli and Proteus mirabilis induced by ampicillin. Whereas those of $E$. coli lysed rapidly in a medium with an osmolality of $234 \mathrm{mOsm}$ per $\mathrm{kg}$ those of Proteus did not. The latter did lyse, however, in a medium of $156 \mathrm{mOsm}$ per $\mathrm{kg}$. Our observations indicate that $\mathrm{L}$ forms of $H$. influenzae can resist osmotic lysis in a medium of 144 mOsm per $\mathrm{kg}$ and are thus even more stable than those of $\mathrm{Pr}$. mirabilis.

These findings have implications which relate to two practical situations-laboratory sensitivity tests and chemotherapy of chronic haemophilus infections. Greenwood and O'Grady (1972), in the light of their observations of the osmotic susceptibility of spheroplasts of Proteus, have indicated the need for specification of osmolality of media used for assessing the sensitivity of organisms to penicillins. We support this view but must point out that it is doubtful whether a medium could be devised with an osmolality sufficiently low to allow lysis of $L$ forms of $\boldsymbol{H}$. influenzae while being at the same time able to support the growth of the normal vegetative forms. Our initial suspicion that $\mathbf{L}$ form stability in broth A might relate to its content of $\mathrm{Mg}^{++}$, and that lysis might occur if this were omitted, was dispelled by failure of lysis in broth B, which contained no added $\mathrm{Mg}^{++}$.

It seems that the practical attitude to adopt at present is to re-emphasize the need to use a light inoculum in tests of sensitivity of $\boldsymbol{H}$. influenzae to penicillins, and presumably also cephalosporins. But even this manoeuvre rather begs the question, 
for we have shown that even with a light inoculum persistent $\mathbf{L}$ forms can be demonstrated microscopically in antibiotic-containing medium showing no macroscopic growth, and the significance of these forms in relation to practical chemotherapy must be considered. The number of such forms relative to the number of organisms in the initial inoculum appears to be small, and it is probable that they can be ignored in the context of therapy of patients with acute infections with little or no underlying impairment of bacterial clearance mechanisms. Patients with advanced chronic bronchopulmonary disease, however, present an entirely different problem. Here local defence mechanisms are impaired to a degree that allows reinvasion of the bronchial mucous membrane by any viable pathogenic bacteria remaining in the respiratory tract after chemotherapy (May 1972) and induction of even a few $L$ forms of $H$. influenzae by a penicillin, followed after treatment by their reversion to normal bacillary forms, could well lead to a relapse of infection after treatment. The likelihood that this may happen in vivo is currently being studied and will be reported elsewhere in due course. Meanwhile it seems pertinent to point out that the osmolality of sputum ranges from 108 to
$361 \mathrm{mOsm}$ per $\mathrm{kg}$ (mean 227 mOsm per $\mathrm{kg}$, Charman, Lopez-Vidriero, and Reid, personal communication) and it must be tentatively concluded that, from this standpoint at least, $\mathrm{L}$ forms of $H$. influenzae could usually survive in the environment provided by respiratory secretions.

We are grateful to Beecham Pharmaceuticals Ltd for a grant to support A.I. and Chas. Pfizer Ltd, for a grant to support S.V.W.

References

Baker, F. J., and Breach, M. R. (1967). Handbook of Bacteriological Technique, 2nd ed., p. 76. Butterworth, London.

Burns, M. W, and Devitt, L. (1972). Amoxycillin in lower respiratory tract infections. Symposium on amoxycillin. Personal communication.

Charman, J., Lopez-Vidriero, M. T., and Reid, L. (1974). Personal communication.

Greenwood, D., and O'Grady, F. (1969). A comparison of the effects of ampicillin on Escherichia coli and Proteus mirabilis. J. med. Microbiol., 2, 435-441.

Greenwood, D., and O'Grady, F. (1972). The effect of osmolality on the response of Escherichia coli and Proteus mirabilis to penicillins. Brit. J. exp. Path., 53, 457-464.

May, J. R. (1972). Chemotherapy of Chronic Bronchitis and Allied Disorders. 2nd ed., pp. 29-34. English Universities Press, London. 